\title{
Evaluasi Penggunaan Pati Ganyong (Canna edulis Kerr.) Sebagai Bahan Pengikat Pada Tablet Kunyah Ekstrak Etanol Daun Kelor (Moringa oleifera L) Dengan Metode Granulasi Basah
}

\author{
Maryatul Kiptiyah ${ }^{1}$, St. Rahmatullah ${ }^{2 *}{ }^{*}$ Wirasti $^{3}$, Urmatul Waznah ${ }^{4}$ \\ 1,2,3,4 Program Studi Sarjana Farmasi Fakultas Ilmu Kesehatan Universitas Muhammadiyah \\ Pekajangan Pekalongan, Indonesia \\ *email: amma88.an@gmail.com
}

\begin{abstract}
Ganyong contains high starch (carbohydrates) which can be used as a binder in tablet formulations. Chewable tablets are intended for people who have difficulty swallowing medicine. One of the chewable tablet preparations is an antacid preparation. Moringa leaves contain substances that are useful as gastroprotection, anti-ulcer, and antioxidants. This study aims to evaluate the use of canna starch as a binder in the chewable ethanol extract of Moringa leaves using wet granulation method. Evaluation on tablets was carried out on Physical Appearance Test, Organoleptic, Size and Weight Uniformity, Hardness, Brittleness, and Taste Response. The data analysis was done qualitatively by referring to the literature book on Solid Preparation Technology Pharmacy Teaching Materials. The three formulas met the requirements in the granule and tablet evaluation test. Close to perfect results are found in formula III with $10 \%$ starch content. Evaluation of granules includes $0.00 \%$ moisture content test, compressibility test $7.89 \%$, angle of repose test 32.210 , flow rate test 4.59 seconds. The evaluation of the tablets included a physical appearance test with no damage, an organoleptic test with a slightly sweet bitter taste, a size uniformity test with a diameter of $12.00 \mathrm{~mm}$ and a tablet thickness of $4.69 \mathrm{~mm}$, a weight uniformity test with an average of $507.9 \mathrm{mg}$, Hardness test $5.16 \mathrm{~kg}$, Fragility test $0.36 \%$, Disintegration Time test 4 minutes 30 seconds, Preference test with a slightly sweet bitter taste.
\end{abstract}

Keywords : Ganyong, Binder, Chewable Tablet, Moringa, Wet Granulation.

\begin{abstract}
Abstrak
Ganyong mengandung pati (karbohidrat) tinggi yang dapat digunakan sebagai bahan pengikat pada formulasi tablet. Tablet kunyah ditujukan untuk orang-orang yang memiliki kesulitan dalam menelan obat. Salah satu sediaan tablet kunyah adalah sediaan antasida. Daun Kelor mengandung zat yang bermanfaat sebagai gastroproteksi, antiulkus, dan antioksidan. Tujuan penelitian ini untuk mengevaluasi penggunaan pati ganyong sebagai bahan pengikat pada tablet kunyah ekstrak etanol daun kelor dengan metode granulasi basah. Evaluasi pada tablet yang dilakukan terhadap Uji Penampilan Fisik, Organoleptis, Keseragaman Ukuran dan Bobot, Kekerasan, Kerapuhan, serta Uji Kesukaan. Analisis data dilakukan secara kualitatif dengan mengacu pada literatur buku Bahan Ajar Farmasi Teknologi Sediaan Solid. Ketiga formula memenuhi syarat dalam uji evaluasi granul dan tablet. Hasil yang mendekati sempurna terdapat pada formula III dengan kadar amilum $10 \%$. Evaluasi granul meliputi uji kadar air 0,00\%, uji kompresibilitas 7,89\%, uji sudut diam 32,210 , uji laju alir 4,59 detik. Evaluasi tablet yang meliputi uji Penampilan fisik tidak ada kerusakan, uji Organoleptis dengan rasa pahit agak manis, uji Keseragaman ukuran dengan diameter $12,00 \mathrm{~mm}$ tebal tablet 4,69 mm, uji Keseragaman bobot dengan rata-ratanya 507,9 mg, uji Kekerasan 5,16 kg, uji Kerapuhan 0,36\%, uji Waktu Hancur 4 menit 30 detik, uji Kesukaan dengan rasa pahit agak manis.
\end{abstract}

Kata Kunci : Ganyong ; Pengikat ; Tablet Kunyah ; Kelor ; Granulasi Basah 


\section{Prosiding Seminar Nasional Kesehatan Lembaga Penelitian dan Pengabdian Masyarakat Universitas Muhammadiyah Pekajangan Pekalongan

\section{Pendahuluan}

Pemanfaatan daun kelor untuk kesehatan atau obat, pada umumnya hanya dikonsumsi langsung dalam bentuk rebusan atau seduhan. Pemanfaatan dengan cara tersebut dinilai kurang efektif dan efisien. Efektif dan efisien yang dimakud yaitu rebusan atau seduhan tidak praktis jika digunakan pada saat diperjalanan. Salah satu upaya untuk mengatasi masalah ini yaitu dengan membuat daun kelor menjadi ekstrak yang diformulasikan pada pembuatan tablet kunyah, karena salah satu keuntungan dari tablet kunyah yaitu mempunyai efek terapi yang cepat, mudah dalam penggunaannya, dan dapat membantu pasien yang susah menelan obat. Kandungan dari zat aktif daun kelor memiliki sifat tahan terhadap panas dan stabil dengan adanya air, dengan sifat dari daun kelor tersebut maka metode pembuatan tablet kunyah ini dibuat dengan metode granulasi basah. Metode granulasi basah dapat memperbaiki sifat alir dengan membentuk granul dan meningkatkan kompaktibilitas bahan sehingga menjadi lebih mudah dikompresi.

Tablet kunyah yaitu tablet yang diformulasikan untuk mengalami disintegrasi / disolusi didalam mukosa mulut. Tablet kunyah biasanya ditujukan untuk anak-anak atau orang dewasa yang mempunyai kesulitan dalam proses menelan. Bentuk dari tablet kunyah diharapkan agar lebih disukai, karena lebih memudahkan dalam penggunaannya dan menyenangkan karena mengandung bahan pemanis.

Tablet kunyah biasanya diantara lain untuk sediaan antibakteri, multivitamin dan antasida, seperti penelitian yang telah dilakukan oleh Setiawan, dkk., (2018) tentang "Pengaruh Pemberian Ekstrak Daun Kelor (Moringa oleifera L) Dosis Bertingkat Terhadap Gambaran Mikroskopis Gaster Tikus Wistar Jantan yang Diinduksi Formalin", daun Kelor dapat mengatasi / mengurangi tukak pada lambung.

Penelitian yang dilakukan Nurul Muflikhah (2017) tentang "Formulasi Sediaan Tablet Kunyah Ekstrak Etanol Daun Kelor (Moringa oleifera L) dengan Penambahan Variasi Pengisi Sorbitol-Sukrosa mengunakan Metode Granulasi Basah", tablet kunyah dicetak menggunakan metode Granulasi Basah. Metode Granulasi Basah adalah metode yang sangat membutuhkan bahan pengikat dan tidak begitu membutuhkan bahan penghancur karena di sini gigi melakukan fungsinya.

Bahan pengikat yang biasa digunakan yaitu pati, pati yang digunakan untuk penelitian adalah pati daru umbi ganyong. Seperti penelitian yang telah dilakukan oleh Indrianti, dkk., (2017) tentang "Fosforilasi Pati Ganyong sebagai Pengikat pada Tablet Parasetamol Menggunakan Sodium Tripoliphosphat", sehingga pati Ganyong dapat digunakan sebagai bahan pengikat untuk pembuatan tablet.

\section{Metode}

Penelitian ini dilakukan secara eksperimental di Laboratorium dengan langkah penelitian yang dilakukan yaitu determinasi tanaman daun kelor (Moringa oleifera $\mathrm{L}$ ), pembuatan simplisia, pembuatan ekstrak daun kelor (Moringa oleifera $\mathrm{L}$ ), pembuatan amilum dari umbi ganyong (Canna edulis Kerr.), pembuatan granul, evaluasi granul, pembuatan tablet kunyah ekstrak daun kelor dengan bahan pengikat amilum ganyong, evaluasi sediaan tablet kunyah ekstrak daun kelor (Moringa oleifera $\mathrm{L}$ ) dengan bahan pengikat amilum ganyong (Canna edulis Kerr.). 


\section{Prosiding Seminar Nasional Kesehatan $\mid \mathbf{2 0 2 1}$ \\ Lembaga Penelitian dan Pengabdian Masyarakat Universitas Muhammadiyah Pekajangan Pekalongan}

\section{A. Bahan Penelitian}

Bahan yang digunakan dalam penelitian ini adalah ekstrak daun kelor (Moringa oleifera L) yang diperoleh dari daerah Keputran Kota Pekalongan Jawa Tengah, amilum dari umbi ganyong (Canna edulis Kerr.) yang diperoleh dari desa Krandegan Paninggaran Kabupaten Pekalongan Jawa Tengah, Manitol, Laktosa, Talk, Mg Stearat, serbuk Magnesium, etanol.

\section{B. Peralatan}

Peralatan yang digunakan dalam penelitian ini adalah neraca analitik (OHAUS PA224), alat pencetak tablet (RRC), friability tester (CS-2), hardness tester (YPJ200B), jouling volumeter (SVM 223), flowing tester (GNL1), corong (Pyrex), moisture tester (MB 25), oven (IKA Oven 125), stopwatch (PC2250A), rotary evaporator (HiYi), jangka sorong (New Deland), pengayak, alat-alat gelas (pyrex).

\section{Prosedur}

\section{Determinasi}

Determinasi Daun Kelor dilakukan di Universitas Ahmad Dahlan, Yogyakarta. Determinasi tanaman bertujuan untuk memastikan keaslian tanaman yang digunakan dalam penelitian.

\section{Pembuatan Simplisia}

Pengambilan simplisia daun kelor yang dipanen dan dikumpulkan pada waktu pagi hari sebelum matahari terbit. Lalu dilakukan sortasi basah untuk memilih daun kelor yang segar dan bagus. Daun kelor dicuci dengan air mengalir. Daun kelor kemudian dikeringkan untuk menurunkan kadar air menggunakan oven pada suhu $50^{\circ} \mathrm{C}$ sampai kering. Kemudian dilakukan sortasi kering untuk memilih simplisia kering yang bermutu baik. Simplisia daun kelor kering diblender dan diayak menggunakan ayakan no 40 Mesh. Serbuk yang diperoleh selanjutnya digunakan untuk pembuatan ekstrak daun kelor.

\section{Pembuatan Ekstrak Daun Kelor (Moringa oleifera $\mathrm{L}$ )}

Sebanyak $500 \mathrm{~g}$ serbuk daun kelor di maserasi menggunakan etanol 96\% sebanyak 3 liter, rendaman pertama sesekali diaduk. Proses maserasi dilakukan dalam 5 hari. Kemudian rendaman disaring menggunakan kain flanel sehingga didapatkan filtrat (filtrat 1 ) dan residu. Residu dimaserasi kembali selama 2 hari dengan etanol 96\% sebanyak 1,5 L, kemudian disaring kembali sehingga didapatkan filtrat (filtrat 2). Selanjutnya filtrat yang telah didapatkan (filtrat $1 \&$ 2) disatukan dalam satu wadah. Kemudian filtrat diuapkan menggunakan rotary evaporator pada suhu $60^{\circ} \mathrm{C}$ sehingga didapatkan ekstrak kental. Hasil ekstrak kental ditimbang dan disimpan dalam wadah yang tertutup dengan baik (BPOM RI, 2013).

\section{Pembuatan Amilum Dari Umbi Ganyong (Canna edulis Kerr.)}

Dilakukan dengan cara umbi ganyong dikupas kulitnya, kemudian dicuci sampai bersih dengan air yang mengalir, umbi ganyong diparut hingga berubah tekstur seperti bubur encer. Selanjutnya hasil parutan umbi ganyong diperas 


\section{Prosiding Seminar Nasional Kesehatan $\mathbf{2 0 2 1}$ Lembaga Penelitian dan Pengabdian Masyarakat Universitas Muhammadiyah Pekajangan Pekalongan}

dengan kain batis hingga tidak dapat diperas lagi. Ampas dicuci lagi dengan air lalu diperas kembali. Pemerasan dilakukan berulang sampai air perasan terlihat jernih. Filtrat yang didapatkan diendapkan di wadah selama 24 jam. Setelah mengendap sempurna, cairan jernih di atasnya di dekantasi sehingga diperoleh endapan amilum ganyong. Endapan amilum kemudian dicuci kembali dengan air hingga diperoleh endapan amilum yang berwarna putih dan bersih. Endapan amilum kemudian dikeringkan di lemari pengering dengan suhu $50^{\circ} \mathrm{C}$ selama 24 jam. Setelah kering, amilum diayak dengan pengayak mesh no. 100.

\section{Pembuatan Granul}

Ekstrak kelor (Moringa oleifera L) dicampur dengan manitol dan laktosa sampai homogen. Lalu ditambah dengan bahan pengikat pati ganyong (Canna edulis Kerr.) yang sebelumnya dilarutkan dengan aquadest panas $11 \mathrm{~mL}$. Bahan pengikat ditambahkan sambil diremas sampai homogen dan membentuk massa granul. Dilakukan pengayakan basah dengan No. mesh 18 dan dikeringkan dengan suhu $57^{\circ} \mathrm{C}$ selama \pm 2 jam. Granul kering diayak kembali dengan no. mesh 20, kemudian ditambahkan talk dan magnesium stearate. Selanjutnya dilakukan pengujian terhadap granul.

6. Evaluasi Granul

a. Uji sifat aliran

Pengujian dilakukan dengan alat Flowing tester. Serbuk granul sebanyak 25 gram dimasukkan pada media corong. Tutup corong dibuka disertai dengan stopwatch yang sudah dinyalakan. Kemudian dilakukan sebanyak 3 kali pengukuran. Syarat mengalir kurang dari 10 detik.

b. Uji kandungan lembab

1gram granul dimasukkan dalam aluminium foil. Lalu ditara dan diukur kadar airnya dengan menekan tombol start maka akan didapat persen (\%) kadar air. Pengukuran dilakukan hingga didapat kadar air yang konstan pada 3 kali pengukuran.

c. Uji bj mampat / kompresibilitas

100 Gram granul dimasukkan kedalam gelas ukur dan dicatat volumenya. Kemudian granul dimampatkan sebanyak 500 kali ketukan dengan alat uji Kompresibilitas. Dicacat perubahan volume yang terjadi. Volume uji sebelum dimampatkan (Vo) dan volume setelah dimampatkan $\left(\mathrm{V}_{1}\right)$.

d. Uji bobot jenis nyata

Granul dimasukkan ke gelas ukur sampai $100 \mathrm{ml}$. Lalu serbuk dikeluarkan dari gelas ukur lalu ditimbang, dihitung bobot jenis nyata.

\section{Pembuatan Tablet Kunyah Ekstrak Daun Kelor (Moringa oleifera $\mathrm{L}$ )}

Tahapan dalam pembuatan tablet kunyah ini menggunakan metode granulasi basah. Langkah-langkah yang diperlukan dalam pembuatan tablet dengan metode ini adalah sebagai berikut: menimbang dan mencampur bahan- 


\section{Prosiding Seminar Nasional Kesehatan Lembaga Penelitian dan Pengabdian Masyarakat Universitas Muhammadiyah Pekajangan Pekalongan}

bahan yang akan digunakan pada fase dalam, seperti: Formula I (Mencampur ekstrak kental 5 gram, Laktosa 26,5 gram, Manitol 12,5 gram, dan ditambahkan bahan pengikat amilum ganyong sebanyak $2 \mathrm{gram}$ ). Formula II (Mencampur ekstrak kental 5 gram, Laktosa 25 gram, Manitol 12,5 gram, dan ditambahkan bahan pengikat amilum ganyong sebanyak 3,5 gram). Formula III (Mencampur ekstrak kental 5 gram, Laktosa 23,5 gram, Manitol 12,5 gram, dan ditambahkan bahan pengikat amilum ganyong sebanyak 5 gram).

Bahan pengikat sudah berbentuk mucilago, lalu diayak menggunakan ayakan mesh 18 , kemudian dikeringkan dengan oven dengan suhu $57^{\circ} \mathrm{C}$ selama \pm 2 jam, setelah itu dilakukan pengayakan kering dengan ayakan 20 mesh, pencampuran fase luar, seperti: Mg Stearat sebanyak 1 gram dan Talk sebanyak 1 gram pada formula I,II dan III. Kemudian pembuatan tablet dengan kompresi.

Prinsip dari metode granulasi basah adalah ekstrak etanol daun kelor, manitol dan laktosa, dicampur homogen, kemudian ditambahkan pengikat amilum ganyong, diayak menjadi granul, pengeringan pada suhu $40-60^{\circ} \mathrm{C}$, pengayakan kering, pencampuran $\mathrm{Mg}$ stearat dan talk dan terakhir dicetak dengan mesin pencetak tablet

Tabel 2.1 Formula Tablet Kunyah Ekstrak Etanol Daun Kelor

\begin{tabular}{lcccl}
\hline Komposisi & $\begin{array}{c}\text { Formula 1 } \\
(\mathbf{\%})\end{array}$ & $\begin{array}{c}\text { Formula 2 } \\
\mathbf{( \% )}\end{array}$ & $\begin{array}{c}\text { Formula 3 } \\
\mathbf{( \% )}\end{array}$ & Fungsi \\
\hline \multicolumn{5}{c}{ Fase Dalam } \\
\hline Ekstrak Daun Kelor & $50 \mathrm{mg}$ & $50 \mathrm{mg}$ & $50 \mathrm{mg}$ & Zat Aktif \\
Manitol & 25 & 25 & 25 & Pemanis \\
Amilum Ganyong & 4 & 7 & 10 & Pengikat \\
Laktosa & ad 100 & ad 100 & ad 100 & Pengisi \\
\hline \multicolumn{5}{c}{ Fase Luar } \\
\hline Mg Stearat & 2 & 2 & 2 & Pelicin \\
Talk & 2 & 2 & 2 & Pelicir \\
\hline Total & 100 & 100 & 100 & \\
\hline
\end{tabular}

8. Evaluasi Tablet Kunyah

a. Uji penampilan fisik

Dilakukan pengamatan penampilan fisik seluruh tablet kunyah ekstrak daun kelor yang dihasilkan seperti capping, cracking, picking dan karakteristik lain yang menandakan adanya kerusakan pada tablet.

b. Uji organoleptis

Dilakukan pengamatan pada tablet uji seperti perubahan warna, bentuk rasa dan bau.

c. Uji keseragaman ukuran

Diameter dan tebal tablet diukur masing-masing 10 tablet dengan menggunakan alat ukur ketebalan dan diameter atau yang biasa digunakan 


\section{Prosiding Seminar Nasional Kesehatan Lembaga Penelitian dan Pengabdian Masyarakat Universitas Muhammadiyah Pekajangan Pekalongan}

yaitu jangka sorong, bila dinyatakan lain, diameter tablet tidak lebih dari tiga kali dan tidak kurang dari empat pertiga tebal tablet.

\section{d. Uji keseragaman bobot}

Ditimbang 20 tablet, dihitung berat rata-rata tiap tablet, kemudian tablettablet tersebut ditimbang satu per satu, tidak boleh lebih dari dua tablet yang masing-masing bobotnya menyimpang dari bobot rata-ratanya lebih besar dari harga yang ditetapkan kolom A dan tidak satu tablet pun yang bobotnya menyimpang dari bobot rata-rataya lebih dari harga yang ditetapkan kolom $\mathrm{B}$.

e. Uji kekerasan

Uji kekuatan tablet dilakukan dengan cara mengambil satu tablet, kemudian diletakan ditengah dan tegak lurus diantara ujung dan plat penekan alat hardness tester. Mula-mula alat pada skala nol, lalu diputar pelan-pelan ke arah kanan sampai tablet pecah menjadi dua. Skala yang ditunjukan dalam kekuatan tablet yaitu $\mathrm{kg} / \mathrm{cm}^{3}$. Menghitung kekerasan tablet satu persatu dengan menggunakan alat penguji hardness tester sebanyak 5 buah tablet. Kemudian dihitung rata-ratanya. Kekerasan standar tablet kunyah 4-7 kg.

f. Uji kerapuhan

Tablet sebanyak 20 tablet yang bobotnya ditimbang, lalu dimasukan kedalam alat rotasi dalam Friabilator Rochese banyak 100 putaran. Dibersihkan debunya, lalu ditimbang kembali. Persentase friabilitas ditetapkan dan kehilangan bobot. Pada tablet kunyah nilai friabilitas sampai $4 \%$ dapat diterima.

g. Uji waktu hancur

Sejumlah 6 tablet dimasukkan ke dalam keranjang alat disintegrator tester, kemudian dimasukkan ke dalam bekerglass yang telah berisi air dengan suhu $36^{\circ} \mathrm{C}-38^{\circ} \mathrm{C}$. Sedalam tidak kurang dari $15 \mathrm{~cm}$, sehingga dapat dinaik-turunkan dengan teratur. Kedudukan kawat kasa pada posisi tertinggi tepat di atas permukaan air dan kedudukan mulut keranjang tepat di permukaan air. Tabung dinaik-turunkan secara teratur. Tablet dinyatakan hancur jika tidak ada bagian yang tertinggal di atas kasa. Dicatat waktu hancur tablet yang terakhir hancur. Waktu yang diperlukan untuk menghancurkan keenam tablet tidak lebih dari 15 menit untuk tablet tidak bersalut (Anonim, 1995).

h. Uji kesukaan

Dipilih 20 responden secara acak, kemudian diminta untuk merasakan dan memberikan tanggapan rasa tablet kunyah ekstrak daun kelor. Setiap responden memiliki kesempatan untuk merasakan ketiga formula tablet kunyah dengan cara memakan dan merasakan dan selanjutnya diberikan air putih untuk mencoba formula selanjutnya. Kemudian responden mengisi angket yang telah diberikan. 
Prosiding Seminar Nasional Kesehatan Lembaga Penelitian dan Pengabdian Masyarakat 2021 Universitas Muhammadiyah Pekajangan Pekalongan

\section{Hasil dan Pembahasan}

\section{Hasil Determinasi}

1b2b3b- Canna edulis Ker Gawl

1b- Moringa oleifera Lam

Tabel 3.1 Randemen

\begin{tabular}{cccc}
\hline Daun & Berat Basah & Berat Serbuk & Randemen (\%) \\
\hline $\begin{array}{c}\text { Daun Kelor (Moringa } \\
\text { oleifera L) }\end{array}$ & $4 \mathrm{Kg}$ & $1 \mathrm{Kg}$ & $25 \%$ \\
$\begin{array}{c}\text { Daun Kelor (Moringa } \\
\text { oleifera L) } \\
\text { Umbi Ganyong } \\
\text { (Canna edulis Kerr.) }\end{array}$ & $500 \mathrm{gram}$ & $40 \mathrm{gram}$ & $8 \%$ \\
\hline
\end{tabular}

Tabel 3.2 Hasil Uji Kompresibilitas

\begin{tabular}{llll}
\hline \multirow{2}{*}{ Kriteria } & \multicolumn{3}{c}{ Formula } \\
\cline { 2 - 4 } & \multicolumn{1}{c}{ I } & \multicolumn{1}{c}{ II } & \multicolumn{1}{c}{ III } \\
\hline B] Nyata $(\mathrm{g} / \mathrm{ml})$ & 0,40 & 0,36 & 0,35 \\
B] Mampat $(\mathrm{g} / \mathrm{ml})$ & 0,44 & 0,38 & 0,38 \\
\% Kompresibilitas & $9,09 \%$ & $5,26 \%$ & $7,89 \%$ \\
\hline \multicolumn{4}{c}{ (Data diolah, 2021) }
\end{tabular}

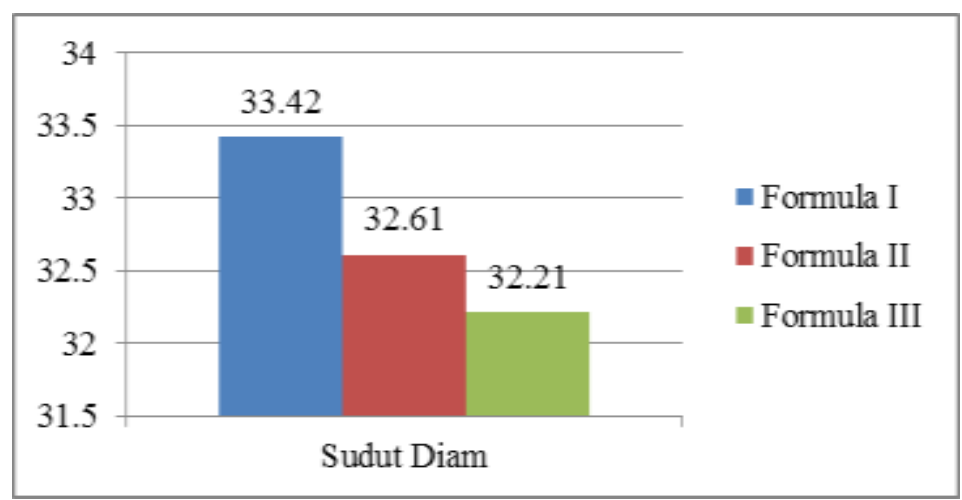

Gambar 3.1 Grafik Evaluasi Uji Sudut Diam Granul (Data diolah, 2021)

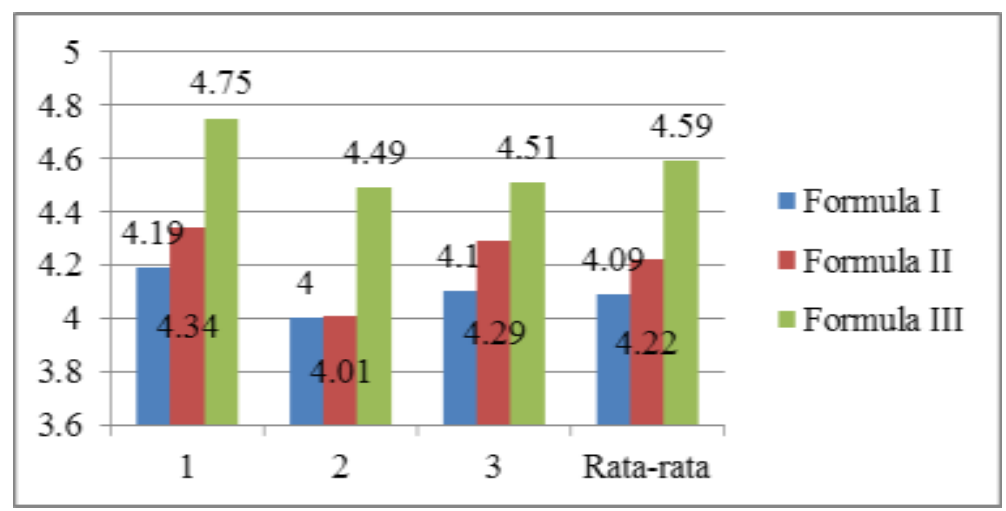

Gambar 3.2 Grafik Evaluasi Uji Laju Alir Granul (Data diolah, 2021) 


\section{Prosiding Seminar Nasional Kesehatan Lembaga Penelitian dan Pengabdian Masyarakat Universitas Muhammadiyah Pekajangan Pekalongan}

Tabel 3.3 Evaluasi Uji Organoleptis Tablet Kunyah

\begin{tabular}{ccccc}
\hline Formula & Bentuk & Warna & Bau & Rasa \\
\hline I & Bulat cembung & Hijau pekat & Khas daun kelor & Pahit \\
II & Bulat cembung & Hijau agak pekat & Khas daun kelor & $\begin{array}{c}\text { Agak pahit } \\
\text { III }\end{array}$ \\
Bulat cembung & Hijau & Khas daun kelor & Pahit agak manis \\
\hline Amilum Ganyong & Serbuk Halus & Putih & Tidak Berbau & Agak manis \\
\hline
\end{tabular}

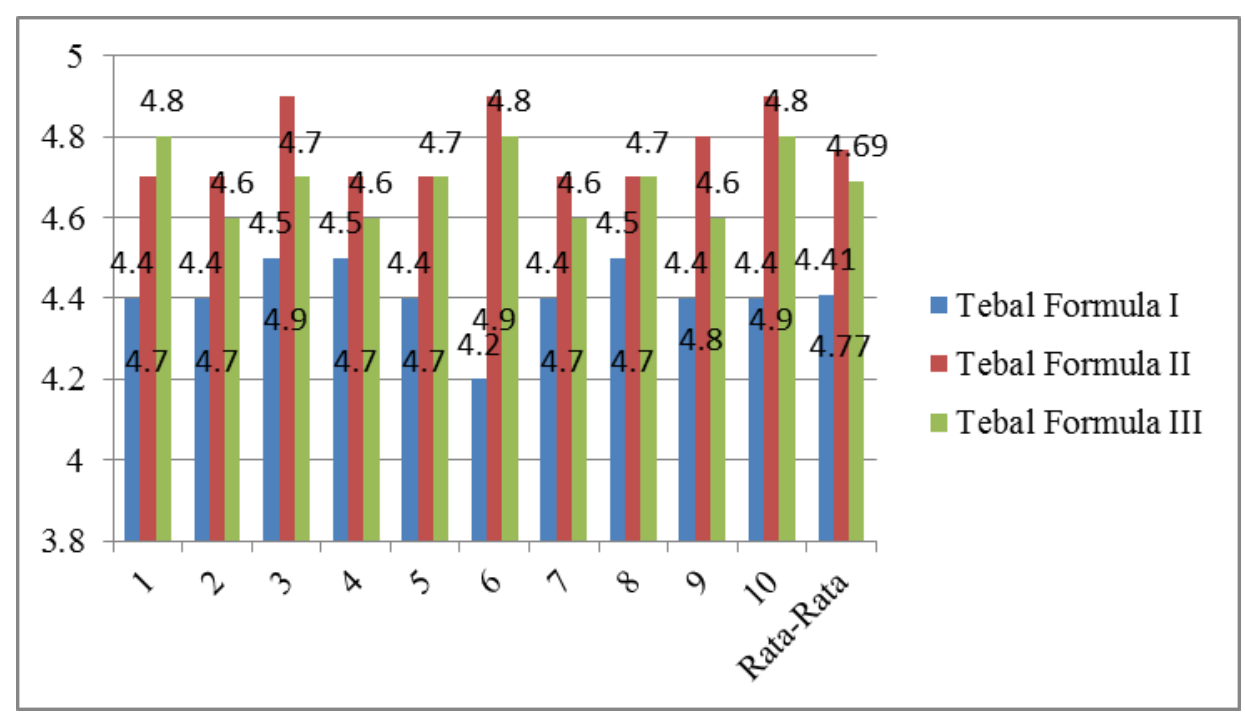

Gambar 3.3 Grafik Evaluasi Uji Keseragaman Ukuran (Data diolah, 2021)

Tabel 3.4 Evaluasi Uji Keseragaman Bobot Kolom A (5\%) \& Kolom B (10\%)

\begin{tabular}{ccccccc}
\hline \multirow{2}{*}{ No. } & \multicolumn{2}{c}{ Formula I } & \multicolumn{2}{c}{ Formula II } & \multicolumn{2}{c}{ Formula III } \\
\cline { 2 - 7 } & Bobot (mg) & \% & Bobot (mg) & \% & Bobot (mg) & \% \\
\hline 1 & 525 & 3,38 & 520 & 1,66 & 500 & 1,55 \\
2 & 524 & 3,19 & 522 & 2,05 & 524 & 3,16 \\
3 & 485 & 4,48 & 529 & 3,42 & 494 & 2,74 \\
4 & 500 & 1,53 & 528 & 3,23 & 500 & 1,55 \\
5 & 500 & 1,53 & 500 & 2,24 & 503 & 0,96 \\
6 & 476 & 6,26 & 485 & 5,18 & 521 & 2,57 \\
7 & 492 & 3,11 & 524 & 2,44 & 520 & 2,38 \\
8 & 508 & 0,04 & 525 & 2,64 & 491 & 3,32 \\
9 & 497 & 2,13 & 500 & 2,24 & 538 & 5,96 \\
10 & 489 & 3,70 & 521 & 1,86 & 525 & 3,36 \\
11 & 520 & 2,40 & 524 & 2,44 & 500 & 1,55 \\
12 & 500 & 1,53 & 491 & 4,00 & 481 & 5,29 \\
13 & 538 & 5,94 & 520 & 1,66 & 500 & 1,55 \\
14 & 493 & 2,91 & 522 & 2,05 & 528 & 3,95 \\
15 & 522 & 2,79 & 521 & 1,86 & 500 & 1,55 \\
16 & 500 & 1,53 & 494 & 3,42 & 522 & 2,77 \\
17 & 520 & 2,40 & 508 & 0,68 & 500 & 1,55 \\
18 & 508 & 0,04 & 485 & 5,18 & 500 & 1,55 \\
19 & 500 & 1,53 & 492 & 3,81 & 511 & 0,61 \\
20 & 500 & 1,53 & 520 & 1,66 & 500 & 1,55 \\
\hline Rata-rata & 507,8 & 2,60 & 511,5 & 2,69 & 507,9 & 2,47 \\
\hline & & & & & (Data diolah, 2021$)$
\end{tabular}




\section{Prosiding Seminar Nasional Kesehatan Lembaga Penelitian dan Pengabdian Masyarakat Universitas Muhammadiyah Pekajangan Pekalongan}

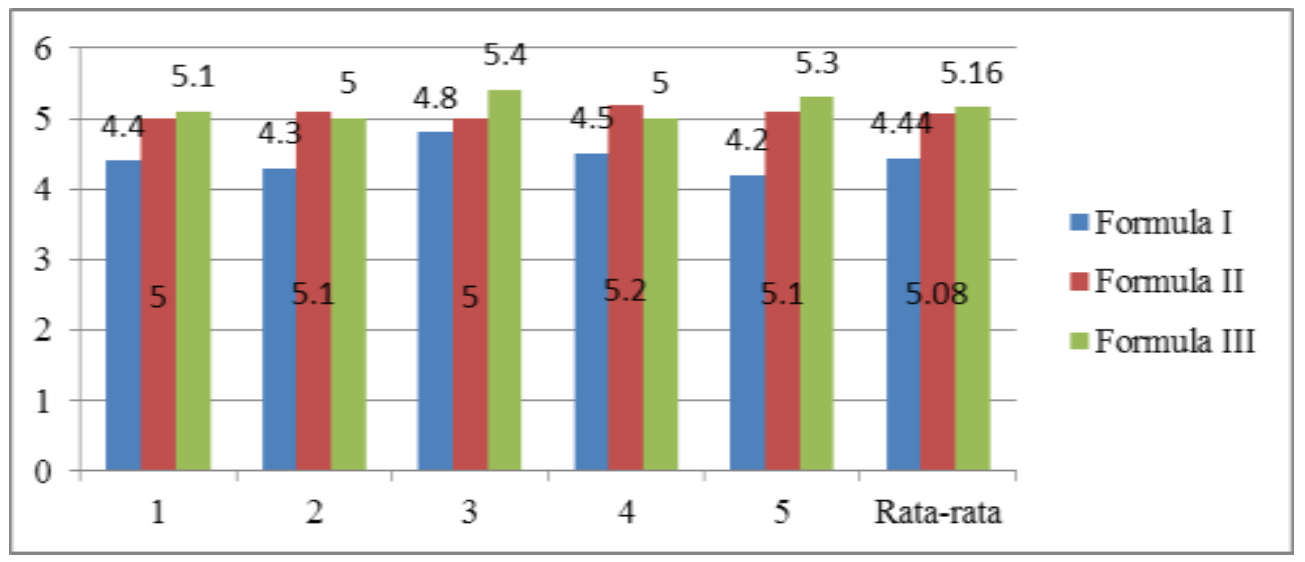

Gambar 3.4 Grafik Evaluasi Uji Kekerasan (Data diolah, 2021)

Tabel 3.5 Evaluasi Uji Kerapuhan

\begin{tabular}{cccccc}
\hline \multicolumn{4}{c}{ Kerapuhan (\%) } \\
\hline \multicolumn{2}{c}{ I } & \multicolumn{2}{c}{ II } & \multicolumn{2}{c}{ III } \\
\hline $\mathrm{W}_{0}$ & $\mathrm{~W}_{1}$ & $\mathrm{~W}_{0}$ & $\mathrm{~W}_{1}$ & $\mathrm{~W}_{0}$ & $\mathrm{w}_{1}$ \\
11,33 & 11,24 & 11,45 & 11,40 & 11,08 & 11,04 \\
\hline $0,79 \%$ & $0,43 \%$ & $0,36 \%$ \\
\hline
\end{tabular}

Keterangan: $\mathrm{w}_{0}=$ Bobot awal (Data diolah, 2021)

$\mathrm{w}_{1}=$ Bobot akhir

Tabel 3.6 Evaluasi Uji Waktu Hancur

\begin{tabular}{cc}
\hline Formula & Waktu Hancur \\
\hline I & 3 menit 20 detik \\
II & 4 menit \\
III & 4 menit 30 detik \\
\hline (Data diolah, 2021)
\end{tabular}

Tabel 3.7 Evaluasi Uji Kesukaan

\begin{tabular}{ccccc}
\hline \multirow{2}{*}{ Formula } & \multicolumn{4}{c}{ Tanggap Rasa Tablet } \\
\cline { 2 - 5 } & Manis agak pahit & Pahit agak manis & Agak pahit & Pahit \\
\hline I & $0 \%$ & $5 \%$ & $20 \%$ & $75 \%$ \\
II & $0 \%$ & $10 \%$ & $25 \%$ & $65 \%$ \\
III & $0 \%$ & $10 \%$ & $40 \%$ & $50 \%$ \\
\hline \multicolumn{2}{r}{} & & \multicolumn{3}{c}{ (Data diolah, 2021 ) }
\end{tabular}

Tabel 3.8 Evaluasi Uji Tanggap Penampilan

\begin{tabular}{ccccc}
\hline \multirow{2}{*}{ Formula } & \multicolumn{4}{c}{ Tanggap Penampilan Tablet } \\
\cline { 2 - 5 } & Sangat Suka & Suka & Kurang Suka & Tidak Suka \\
\hline I & $65 \%$ & $25 \%$ & $10 \%$ & $0 \%$ \\
II & $50 \%$ & $45 \%$ & $5 \%$ & $0 \%$ \\
III & $40 \%$ & $50 \%$ & $10 \%$ & $0 \%$ \\
\hline \multicolumn{2}{r}{} & & \multicolumn{3}{c}{ (Data diolah, 2021) }
\end{tabular}




\section{Prosiding Seminar Nasional Kesehatan $\mid 2021$ Lembaga Penelitian dan Pengabdian Masyarakat Universitas Muhammadiyah Pekajangan Pekalongan}

\section{Pembahasan}

Langkah awal yang dilakukan dalam penelitian adalah determinasi tanaman. Tujuan dari determinasi adalah untuk memastikan keaslian dari tanaman yang digunakan pada penelitian. Determinasi dilakukan di Laboratorium Biologi Fakultas Sains dan Teknologi Terapan Universitas Ahmad Dahlan. Hasil determinasi yang didapat menyatakan bahwa tanaman yang digunakan adalah Daun Kelor (Moringa oleifera L) dan umbi Ganyong (Canna edulis Kerr.)

Proses pembuatan simplisia dengan mengumpulkan dan menyortir daun kelor yang dipetik pada pagi hari sebelum matahari terbit. Setelah penyortiran, daun kelor dicuci dengan air mengalir, ditiriskan lalu dikeringkan dengan oven pada suhu $50^{\circ} \mathrm{C}$ selama 24 jam. Kemudian dihasilkan daun kelor yang kering. Daun tersebut disortir kembali dengan tujuan memilih daun yang berkualitas bagus. Daun kelor kering yang setelah melewati penyortiran ditimbang kembali dan didapatkan bobot sebesar $2 \mathrm{Kg}$. Daun kelor kering lalu dihaluskan menggunakan alat blender dan disaring menggunakan ayakan mesh nomor 40. Tujuan dari pengayakan yaitu untuk menghasilkan ukuran serbuk yang sama sehingga mempermudah serbuk tersebut terdispersi sempurna saat pengadukan pada proses maserasi dengan pelarut yang digunakan. Setelah proses pengayakan dihasilkan bobot serbuk sebesar $1 \mathrm{Kg}$.

Perhitungan randemen dilakukan bertujuan untuk menentukan perbandingan jumlah ekstrak yang diperoleh dari suatu bahan terhadap berat awal simplisia, serta untuk mengetahui banyaknya bioaktif yang terkandung dalam bahan yang terekstraksi.

Serbuk daun kelor kemudian diproses untuk menjadi ekstrak. Serbuk yang dibutuhkan untuk membuat ekstrak sebanyak 500 gram yang dimaserasi dengan etanol $96 \%$ sebanyak 3 Liter. Proses maserasi dilakukan selama 5 hari. Kemudian rendaman disaring hingga didapatkan filtrat (filtrat I) dan residu. Residu terserbut dimaserasi kembali selama 2 hari dengan etanol 96\% sebanyak 1,5 Liter dan disaring hingga mendapatkan filtrat (filtrat II). Selanjutnya filtrat yang didapat dari proses maserasi digabung dan dikentalkan dengan menggunakan alat Rotary evaporator pada suhu $60^{\circ} \mathrm{C}$. Ekstrak etanol daun kelor yang dihasilkan berupa ekstrak kental yang berwarna hijau kecokelatan, memiliki bau yang khas dan rasa yang sangat pahit. Kadar air ekstrak etanol daun kelor sebesar 0,50\%. Hasil ini sesuai dengan persyaratan menurut BPOM RI, 2004, yang menyatakan bahwa kadar air ekstrak tidak boleh lebih dari 10,8\%. Randemen ekstrak yang dihasilkan dari simplisia sebanyak 500 gram adalah sebanyak $8 \%$.

Langkah selanjutnya adalah pembuatan amilum yang akan digunakan sebagai bahan pengikat pada pembuatan tablet kunyah. Pemilihan menggunakan amilum dari umbi ganyong karena kelebihan dari umbi ganyong yang memiliki karakteristik lengket, kadar amilosa didalam umbi ganyong juga tinggi yaitu 42,40\%. Sedangkan, kadar amilosa pada pati beras sebesar 25,56\%, pati jagung $25,97 \%$, pati gandum $17,37 \%$, serta pati singkong 30,61\%. Tingginya kadar amilosa mempunyai kemampuan membentuk gel dan cocok untuk bahan pengikat. Struktur amilosa memungkinkan pembentukan ikatan hidrogen antar molekul glukosa penyusunnya dan selama pemanasan mampu membentuk jaringan tiga dimensi yang dapat merangkap air sehingga menghasilkan gel yang kuat. Umbi ganyong yang terkumpul sebanyak 95 kg, 


\section{Prosiding Seminar Nasional Kesehatan $\mid 2021$ Lembaga Penelitian dan Pengabdian Masyarakat Universitas Muhammadiyah Pekajangan Pekalongan}

kemudian dilakukan pengupasan dan pencucian umbi ganyong dengan air bersih yang mengalir, hal ini dilakukan untuk menghilangkan kotoran dan benda asing yang masih menempel pada umbi ganyong.

Umbi ganyong diparut dengan parutan hingga menjadi bubur hal ini dilakukan untuk memperkecil ukuran sehingga akan mempermudah proses pemerasan. Kemudian dilakukan penyaringan menggunakan kain putih dengan tujuan untuk memisahkan ampas dengan cairan filtrat yang mengandung amilum. Hasil filtrat kemudian ditambahkan air dan diendapkan selama 24 jam tujuannya agar amilum dapat mengendap dan tidak tersisa pada cairan filtrat sehingga randemen amilum yang dihasilkan nantinya lebih baik. Hasil endapan dibilas dengan air dan diendapkan kembali sampai 2 kali, dibuang cairan diatasnya. Endapan yang dihasilkan memiliki tekstur yang halus namun lembek karena masih terdapat kandungan airnya, sehingga dilakukan pengeringan dalam oven pada suhu $50^{\circ} \mathrm{C}$ sampai kering agar amilum yang dihasilkan terhindar dari pertumbuhan mikroorganisme. Amilum yang dihasilkan setelah pengeringan berupa gumpalan kering dengan tekstur halus. Dilakukan pengayakan menggunakan ayakan mesh nomor 100 untuk mendapatkan serbuk halus sesuai dengan persyaratan amilum pada Farmakope Indonesia Edisi IV. Dari proses tersebut, bobot amilum yang didapatkan $1 \mathrm{Kg}$ amilum kering dan bersih.

Amilum ganyong yang sudah jadi perlu dilakukan evaluasi amilum. Evaluasi amilum ganyong yang dilakukan adalah uji organoleptis dan uji kadar air (kelembapan). Uji organoleptis meliputi pengujian pada bentuk, warna, rasa dan bau. Amilum ganyong yang dihasilkan berupa serbuk halus, memiliki warna putih, tidak berbau dan rasa yang agak manis. Warna putih tersebut berasal dari umbi ganyong yang warnanya putih.

Amilum ganyong yang sudah dikeringkan kemudian di uji kadar air. Kandungan air pada amilum ganyong adalah sebesar $1 \%$. Hal ini menunjukkan bahwa hasil tersebut memenuhi syarat menurut Farmakope Indonesia edisi IV bahwa kadar air amilum yang diperbolehkan adalah tidak lebih dari 15\%. Kadar air yang tinggi pada suatu sampel dapat menyebabkan terjadinya pertumbuhan mikroba dan terjadinya reaksi enzimatik yang dapat berpengaruh pada kualitas sampel hingga mengakibatkan kerusakan pada sampel (Ifmaily,2018).

Dilakukan proeses pembuatan tablet setelah melalui evaluasi amilum ganyong. Pembuatan tablet diawali dengan pembuatan granul. Granul dibuat dengan mencampurkan bahan fase dalam hingga homogen, kemudian menyiapkan aquadest panas untuk membuat mucilago amilum ganyong sebagai bahan pengikat. Mucilago amilum yang dihasilkan berupa suspensi bewarna cokelat dan agak kental.

Pembuatan tablet kunyah pada penelitian ini dibuat secara granulasi basah, metode tersebut digunakan agar memperoleh sifat alir dan kompresibilitas yang baik sehingga akan didapatkan tablet kunyah yang memenuhi persyaratan. Memilih menggunakan metode granulasi basah karena agar dapat meningkatkan sifat alir atau kemampuan kempa yang dilakukan dengan cara mencampur zat aktif dan eksipien/bahan tambahan menjadi partikel yang lebih besar dengan penambahan bahan pengikat dalam jumlah yang tepat hingga didapatkan massa granul yang siap dicetak. Selain itu, bahan pengikat yang dibuat mucilago dapat meningkatkan daya ikat 


\section{Prosiding Seminar Nasional Kesehatan $\mid 2021$ Lembaga Penelitian dan Pengabdian Masyarakat Universitas Muhammadiyah Pekajangan Pekalongan}

antar partikel dari amilum ganyong pada campuran serbuk. Metode cetak langsung tidak dapat digunakan karena metode ini memiliki kesulitan dalam pemilihan bahan tambahan, yang dimana bahan tambahannya harus bersifat mudah mengalir, kompresibilitas yang baik, kohesifitas dan adhesifitas yang baik. Sedangkan, ada salah satu bahan tambahan dalam formula tablet kunyah yang digunakan yaitu manitol dimana sifat alirnya buruk. Metode granulasi kering tidak digunakan karena penggunaan metode ini menghasilkan banyak debu saat proses pemecahan slug yang banyak kemungkinan menyebabkan hilangnya bahan tablet sehingga ketercapai jumlah tablet yang tercetak tidak sesuai.

Setiap bahan pada formula yang digunakan memiliki fungsi yang berbeda. Laktosa digunakan sebagai bahan pengisi sekaligus pemanis pada seluruh formula. Manitol digunakan sebagai bahan pemanis, dan Amilum ganyong digunakan sebagai bahan pengikat dalam bentuk mucilago pada seluruh formula. Pada tablet kunyah tidak menggunakan bahan penghancur (desintgrant). Hal ini disebabkan tablet kunyah dimaksudkan untuk hancur perlahan di mulut menggunakan bantuan gigi. Jika ditambahkan bahan penghancur tablet justru tidak melarut tetapi terdesintegrasi (hancur) dan akhirnya meninggalkan residu didalam mulut yang akan mengganggu kenyamanan pasien.

Proses pembuatan tablet yang pertama yaitu mengayak satu-persatu bahan fase dalam yaitu laktosa dan manitol, dengan menggunakan ayakan mesh nomor 20. Dilakukan pengayakan bertujuan untuk memperoleh ukuran yang sama untuk masingmasing bahan sehingga dapat mempermudah pencampuran dan homogen. Kemudian ditambah ekstrak daun kelor sebagai zat aktif dalam bentuk ekstrak kental. Proses pencampuran dilakukan secara bertahap dari bahan yang jumlahnya sedikit sampai yang paling banyak sehingga dapat dihasilkan campuran yang homogen.

Metode pembuatan tablet yang digunakan pada penelitian ini berupa granulasi basah sehingga perlu dilakukan granulasi terlebih dahulu dengan menambahkan bahan pengikat basah pada campuran serbuk. Pengikat basah yang digunakan yaitu mucilago amilum ganyong pada masing-masing konsentrasi ditambahkan pelahan-lahan ke dalam campuran serbuk sambil di remas sehingga membentuk massa granul. Selain banyaknya pelarut yang digunakan, lama pencampuran dan pengadukan menjadi perhatian penting dalam pembuatan granul. Setelah terbentuk massa granul basah, dilakukan pengayakan granul dengan ayakan mesh nomor 18 dengan tujuan untuk meningkatkan luas permukaan granul sehingga akan lebih mudah dikeringkan.

Pengeringan granul dilakukan pada suhu $50^{\circ} \mathrm{C}$ sampai dihasilkan granul kering. Tujuan dari proses pengeringan yaitu untuk menghilangkan pelarut yang digunakan pada saat proses granulasi dan mengurangi kelembapan (Lachman, dkk., 2011). Granul kering yang dihasilkan diayak dengan menggunakan ayakan mesh nomor 20 dengan tujuan granul memiliki ukuran yang sama agar dapat mengisi rongga cetakan tablet secara merata (Ansel, 2014).

Granul yang sudah kering lalu ditimbang dan dilakukan evaluasi granul sebelum di kempa atau di cetak. Evaluasi granul terdiri dari uji kadar air, kompresibilitas, dan sifat alir (sudut diam dan laju alir). Berdasarkan hasil kadar air pada formula I, II dan III diperoleh nilai kadar air yang sama yaitu sebesar 0,00\%. Kadar air dipengaruhi oleh 


\section{Prosiding Seminar Nasional Kesehatan Lembaga Penelitian dan Pengabdian Masyarakat Universitas Muhammadiyah Pekajangan Pekalongan}

lama pengeringan pada granul karena semakin lama pengeringan maka semakin kecil nilai kadar air yang dihasilkan. Kadar air juga berkaitan pada laju alir, hal ini sesuai dengan penelitian yang dilakukan oleh Kartika (2012) yang menyatakan bahwa semakin tinggi kadar air yang terkandung pada granul maka gaya kohesifitas antar partikel semakin besar yang akan mengurangi kemampuan granul untuk mengalir.

Uji yang selanjutnya adalah uji kompresibilitas yang bertujuan untuk mengetahui tentang sifat granul dalam membentuk massa yang kompak dan stabil jika diberi tekanan. Pada Uji Kompresibilitas melibatkan perhitungan Uji Bj Bulk dan Uji Bj Mampat. Uji Bulk dilakukan dengan menimbang bobot granul yang dimasukkan ke dalam gelas ukur $100 \mathrm{~mL}$ sebelum dilakukan pengetapan. Setelah proses pengetapan dilakukan akan dihasilkan beberapa volume yang berbeda. Apabila hasil volume tidak berubah setelah $3 x$ pengetapan maka volume tersebut disebut volume konstan, yang nantinya akan digunakan untuk perhitungan Uji Bj Mampat. Hasil perhitungan Uji Bj Bulk dan Uji Bj Mampat inilah yang akan digunakan untuk perhitungan Uji Kompresibilitas. Hasil uji kompresibilitas menunjukkan bahwa formula I, II, dan III memiliki persen kompresibilitas masuk pada rentang 5-15\% dengan sifat aliran sangat baik (Siregar \& Wikarsa, 2015). Hasil uji kompresibilitas dari formula I, II, dan III berbeda disebabkan oleh ukuran pada granul, kerapatan dan porositas granul, serta volume konstan pada uji pemampatan. Hal ini sesuai dengan penelitian yang sudah dilakukan oleh Amiruddin $d k k$., (2021) yang menyatakan bahwa ukuran granul yang besar dan berongga memiliki ketahanan terhadap pemampatan rendah sehingga lebih kompresibel.

Granul selanjutnya di uji dengan sifat alir yang terdiri dari uji sudut diam dan laju alir granul. Uji sudut diam dan laju alir adalah pengujian yang berkesinambungan karena laju alir menggambarkan tentang lajunya granul mengalir pada corong. Sedangkan, granul yang mengalir kebawah dari corong dan membentuk kerucut itu yang digunakan untuk perhitungan sudut diam. Syarat sudut diam yang sangat baik adalah kurang dari $25^{\circ}$. Jika sudut diam berada pada rentang 25-30 maka sifat alir granul baik. Jika sudut diam berada pada rentang 30-400 maka sifat alir granul sedang. Sedangkan, jika sudut diam berada pada rentang lebih dari $40^{\circ}$ maka granul memiliki sifat alir yang sangat buruk.

Hasil pengujian sudut diam menunjukkan bahwa masing-masing formula memiliki sudut diam yang istimewa dengan nilai rata-rata sudut terkecil $32,21^{\circ}$ pada Formula III dan paling besar pada Formula I sebesar $33,42^{\circ}$, sehingga adanya perbedaan variasi kadar amilum ganyong pada formula mempengaruhi sudut diam dari massa granul. Faktor lain yang menyebabkan perbedaan pada hasil sudut diam masingmasing formula adalah ukuran dari partikel granul yang dialirkan dan besar dan kecilnya gaya tarik dan gaya gesek antar partikel. Semakin kecil sudut diam semakin baik karena sudut diam berhubungan dengan granul yang akan dicetak yang dimana harus dapat teratur dan mudah mengalir kedalam alat pencetak tablet, dengan granul yang mudah mengalir tersebut akan menghasilkan tablet yang bobotnya seragam. Hal ini sesuai dengan penelitian yang dilakukan oleh Egeten $d k k_{.}$, (2016) yang menunjukkan hasil sudut diamnya kisaran $30-40^{\circ}$. Pada penelitian yang dilakukan oleh Husni $d k k$. , (2020) yang menyatakan bahwa sudut diam diantara 20-400 masih dapat 


\section{Prosiding Seminar Nasional Kesehatan Lembaga Penelitian dan Pengabdian Masyarakat Universitas Muhammadiyah Pekajangan Pekalongan}

diterima karena menunjukkan aliran baik. Sedangkan, jika pada $50^{\circ}$ menandakan bahwa granul susah untuk mengalir. Dapat disimpulkan bahwa sudut diam yang terbaik yaitu pada formula III karena sudut diamnya kecil dibandingkan formula lainnya.

Uji selanjutnya yang dilakukan adalah pengukuran laju alir pada granul. Kecepatan alir granul menunjukkan jumlah granul yang mengalir tiap detik. Waktu alir granul dipengaruhi oleh bentuk granul, ukuran granul, kondisi permukaan dan kelembapan granul. Semakin granul lembab akan memperlama waktu alir. Hal ini disebabkan karena granul yang lembab akan cepat menggumpal dan menempel antara partikel lainnya. Sehingga, granul sulit mengalir pada alat. Waktu alir berpengaruh terhadap keseragaman bobot tablet, dimana granul yang memiliki sifat alir baik akan mengisi ruang kompresi dengan konstan dan tidak adanya rongga didalam tablet. Sehingga, tablet yang dihasilkan memiliki bobot yang seragam dan kadar zat aktif yang juga seragam.

Syarat dari waktu alir granul yaitu 100 gram granul mengalir pada waktu kurang dari 10 detik. Tujuan dari uji ini untuk mengetahui baik/tidaknya granul mengalir. Pengujian pada formula I dengan 3x replikasi menghasilkan rata-rata waktu 4,09 detik. Pada pengujian formula II dengan $3 x$ replikasi menghasilkan rata-rata waktu 4,22 detik. Serta pada pengujian formula dengan $3 x$ replikasi menghasilkan rata-rata waktu 4,59 detik. Ketiga formula tersebut memenuhi syarat kurang dari 10 detik meskipun ada perbedaan waktu. Hal ini sesuai dengan penelitian yang dilakukan oleh Khaidir $d k k$., (2015) yang menyatakan bahwa perbedaan hasil dari uji sifat alir dapat disebabkan dari beberapa faktor salah satunya yaitu perbedaan permukaan granul dari tiap formula yang berbeda.

Granul yang sudah dievaluasi kemudian ditambahkan bahan fase luar seperti magnesium stearat dan talk hingga homogen, lalu diayak menggunakan ayakan mesh No. 20 untuk menghasilkan ukuran granul yang seragam. Kemudian granul dicetak hingga menghasilkan tablet kempa.

Tablet yang sudah tercetak kemudian dilakukan evaluasi tablet yang terdiri dari uji penampilan fisik, uji organoleptis, uji keseragaman ukuran, uji keseragaman bobot, uji kekerasan tablet, uji kerapuhan tablet, uji waktu hancur tablet dan uji kesukaan. Dari pengujian tersebut mempunyai syarat tertentu sesuai dengan literatur.

Uji penampilan fisik dilakukan dengan cara mengamati penampilan fisik dari tablet kunyah seperti capping, cracking, picking dan karakteristik lain yang menandakan adanya kerusakan pada tablet kunyah. Dari formula I, II, dan III tersebut tidak ditemukan capping, cracking, picking pada tablet yang menandakan tidak adanya kerusakan tablet. Sehingga dapat disimpulkan bahwa amilum ganyong dapat digunakan sebagai bahan pengikat pada tablet kunyah, meskipun ada perbedaan jumlah amilum ganyong yang diberikan pada ketiga formula tersebut.

Uji organoleptis dilakukan dengan cara mengamati penampilan fisik dari tablet kunyah berupa bentuk, warna, bau dan rasa. Berdasarkan hasil pengamatan formula I, II, dan III memiliki bentuk bulat cembung, berwarna hijau khas warna daun, bau khas daun kelor dan rasa yang pahit. Adanya perbedaan warna antara masing-masing formula disebabkan oleh perbedaan jangka waktu pada pengeringan granul dan 


\section{Prosiding Seminar Nasional Kesehatan $\mid 2021$ Lembaga Penelitian dan Pengabdian Masyarakat Universitas Muhammadiyah Pekajangan Pekalongan}

perbedaan pada kadar amilum. Ketiga formula tersebut menghasilkan tablet yang memiliki rasa pahit disebabkan oleh ekstrak daun kelor yang memang memiliki rasa pahit. Sehingga ekstrak daun kelor tidak disarankan untuk dijadikan tablet kunyah, yang seharusnya memberikan rasa enak di mulut ketika dikunyah. Selain dari ekstraknya, pemilihan bahan pengisi yang kurang tepat seperti laktosa yang memiliki rasa tidak terlalu manis serta penggunaan bahan pemanis yang tidak dikombinasi sehingga tidak dapat menutupi rasa dari ekstrak kelor yang pahit dengan sempurna. Warna pada tiap formula tablet juga berbeda. Hal ini disebabkan karena kadar amilum yang berbeda. Untuk warna dari amilum ganyong sendiri adalah putih. Sehingga, semakin banyak kadar amilumnya akan berpengaruh pada warna tablet. Pada formula I dengan warna hijau pekat (amilum 4\%), formula II dengan warna hijau agak pekat (amilum 7\%), formula III dengan warna hijau (amilum 10\%).

Uji selanjutnya adalah uji keseragaman ukuran. Pengujian ini dilakukan dengan mengukur masing-masing 10 tablet tiap formula menggunakan alat jangka sorong. Ketebalan dan dimensi tablet dipengaruhi oleh tekanan, maka perbedaan ketebalan tablet lebih dipengaruhi oleh tekanan yang diberikan pada saat pencetakan tablet. Dari data yang diperoleh dapat disimpulkan bahwa ketiga formula mempunyai diameter tablet yang tidak lebih dari 3 kali tebal tablet dan tidak kurang dari satu sepertiga tebal tablet. Dari data pada tabel keseragaman ukuran dapat disimpulkan bahwa perbedaan konsentrasi bahan pengikat tidak memberikan perbedaan signifikan pada ukuran tablet yang dihasilkan. Rata-rata diameter dari ketiga formula yaitu $12,00 \mathrm{~mm}$ dan rata-rata tebal tablet pada formula I yaitu $4,41 \mathrm{~mm}$, formula II yaitu 4,7 mm, serta pada formula III yaitu 4,69 mm. Menurut Riawati (2013) keseragaman ukuran menggambarkan reproduksibilitas dan keseragaman kandungan pada bobot tablet.

Uji selanjutnya adalah uji keseragaman bobot. Keseragaman bobot dilakukan bertujuan untuk mengetahui keragaman sediaan dan memastikan bahwa setiap tablet mengandung kadar obat atau bahan aktif yang tepat dan homogen. Hasil pengujian menunjukkan bahwa semua formula tablet kunyah memenuhi syarat keseragaman bobot sesuai dengan Farmakope Indonesia edisi III, yaitu tablet dengan bobot lebih dari $300 \mathrm{mg}$ tidak boleh lebih 2 tablet yang bobotnya menyimpang dari kolom A (5\%) dan tidak boleh ada satupun tablet yang bobotnya menyimpang dari kolom B (10\%). Keseragaman bobot dipengaruhi oleh sifat alir dari massa granul yang akan dicetak, semakin baik sifat alir maka granul akan mengalir secara bebas sehingga die mesin pencetak tablet terisi dengan baik dan menghasilkan tablet yang memiliki bobot yang seragam Hasil pada tabel keseragaman bobot, rata-rata bobot tablet pada formula I yaitu $507,8 \mathrm{mg}$, formula II yaitu $511,5 \mathrm{mg}$ dan pada formula III yaitu $507,9 \mathrm{mg}$. Dapat disimpulkan bahwa 20 tablet dari ketiga formula memenuhi syarat karena tidak ada tablet yang bobot rata-ratanya menyimpang dari kolom B dan tidak lebih dari 2 tablet yang bobot rata-ratanya menyimpang dari kolom $A$. Hal ini sesuai dengan penelitian yang dilakukan oleh Khaidiri $d k k_{.},(2015)$ yang menyatakan bahwa hasil bobot ratarata tablet dapat berbeda namun seragam. Karena, keseragaman bobot berkaitan dengan waktu alir granul yang tiap formulanya juga hampir seragam.

Uji kekerasan tablet bertujuan untuk memberikan gambaran kekuatan tablet terhadap goncangan mekanik yang mungkin terjadi selama proses penyimpanan dan 


\section{Prosiding Seminar Nasional Kesehatan $\mid 2021$ Lembaga Penelitian dan Pengabdian Masyarakat Universitas Muhammadiyah Pekajangan Pekalongan}

pendistribusian. Syarat dari kekerasan tablet kunyah adalah antara $4 \mathrm{~kg}$ sampai $7 \mathrm{~kg}$ (Hadisoewignyo dan Fudholi, 2013). Dari ketiga formula yang digunakan, hasil yang didapat memenuhi persyaratan dengan nilai rata-rata kekerasan 4,44 - 5,16 Kp. Hasil ini disebabkan oleh penambahan amilum sebagai bahan pengikat memberikan kekerasan yang berbeda, semakin banyak amilum yang diberikan semakin keras tablet yang dihasilkan. Karena, amilum ganyong dapat mengikat dengan sempurna. Dari data pada tabel kekerasan tablet, dapat disimpulkan bahwa tablet kunyah dari tiap formula menghasilkan kekerasan tablet yang berbeda. Namun, hal ini sesuai dengan penelitian yang dilakukan oleh Khaidiri $d k k .$, (2015) yang menyatakan bahwa kekerasan tablet berkaitan dengan waktu hancur dan kerapuhan tablet. Semakin tinggi kekerasan pada tablet maka semakin rendah kerapuhan tablet dan semakin lama waktu yang dibutuhkan tablet untuk hancur.

Uji kerapuhan tablet digunakan untuk mengetahui ketahanan tablet selama proses distribusi dan penyimpanan, serta menunjukkan banyaknya zat yang terkikis akibat gesekan ketika melawan tekanan mekanik. Kerapuhan tablet berhubungan dengan kekerasan tablet dimana semakin tinggi kekerasan tablet semakin kecil nilai kerapuhannya. Dari ketiga formula yang digunakan, hasil yang diperoleh memenuhi persyaratan kerapuhan tablet. Hal ini sesuai dengan penelitian yang dilakukan oleh

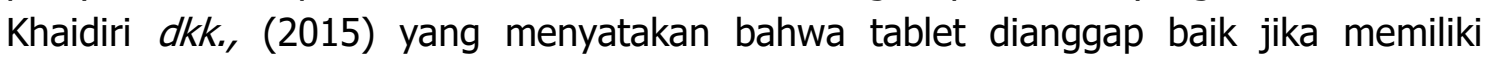
kerapuhan kurang dari $1 \%$. Bobot awal dalam keterangan adalah bobot tablet sebelum dimasukan pada alat. Sedangkan, bobot akhir adalah bobot tablet yang sudah mengalami putaran pada alat friabily tester. Sebelum dan sesudah melakukan uji kerapuhan, tablet yang akan diuji harus dibebasdebukan dahulu. Agar tidak ada debu yang menempel pada tablet uji. Hasil prosentase kerapuhan tablet pada formula I adalah $0,79 \%$, formula II yaitu $0,43 \%$ dan formula III adalah 0,36\%. Dari hasil ketiga formula tersebut memenuhi syarat karena kurang dari $1 \%$. Perbedaan hasil pada tiap formula berhubungan dengan kadar amilum yang digunakan. Semakin tinggi kadar amilum yang diberikan maka amilum dapat mengikat sempurna dan tablet menjadi keras sehingga tablet sulit untuk rapuh. Dapat disimpulkan bahwa tablet yang paling kuat yaitu pada formula III dengan prosentase kerapuhan yang kecil.

Tahapan uji selanjutnya adalah uji waktu hancur yang bertujuan untuk menetapkan batas waktu hancur pada masing-masing formula hingga sediaan yang tertinggal pada kasa alat uji tidak memiliki inti yang jelas. Waktu hancur tablet berkaitan dengan konsentrasi amilum ganyong sebagai bahan pengikat pada formula dimana semakin tinggi konsentrasi bahan pengikat maka semakin lama waktu hancur yang dibutuhkan, hal ini disebabkan bahan pengikat meningkatkan kekompakkan massa tablet yang membuat tablet semakin lama terkikis dan terlarut. Uji waktu hancur dilakukan dengan air pada area keranjang dengan suhu $37^{\circ} \mathrm{C}$, yang memang disesuaikan dengan suhu tubuh manusia. Dari ketiga formula yang diujikan, hasil yang diperoleh memenuhi persyaratan waktu hancur tablet kurang dari 15 menit. Dari hasil ketiga formula tersebut, formula yang paling lama hancur adalah formula III, yang sebanding dengan hasil uji kekerasan tablet dimana tablet pada formula III memiliki hasil uji kekerasan yang paling tinggi. Dari data pada tabel waktu hancur dapat disimpulkan bahwa semakin tinggi kadar amilum pengikat semakin lama tablet untuk 


\section{Prosiding Seminar Nasional Kesehatan $\mid 2021$ Lembaga Penelitian dan Pengabdian Masyarakat Universitas Muhammadiyah Pekajangan Pekalongan}

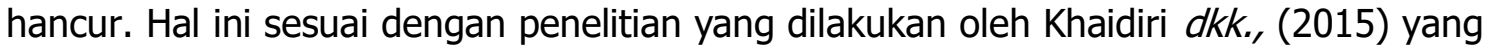
menyatakan bahwa semakin besar jumlah air yang masuk ke dalam pori-pori tablet maka jarak antar partikel akan semakin dekat dan akan hancur dengan waktu yang singkat.

Uji kesukaan dilakukan dengan cara memilih 20 responden. Setiap responden mendapatkan kesempatan untuk merasakan ketiga sampel dari formula tablet kunyah dengan cara mengunyah dan merasakan tablet. Setiap pergantian formula responden diberikan air putih untuk menetralkan mukosa mulut. Para responden diberikan angket yang sudah disediakan. Didalam angket yang telah disediakan berisi tentang tanggapan rasa dan penampilan tablet. Tanggap rasa dikelompokkan dari tingkat manis agak pahit (1), pahit agak manis (2), agak pahit (3) dan pahit (4). Segi penampilan fisik dikelompokkan menjadi sangat suka (1), suka (2), kurang suka (3), dan tidak suka (4). Yang dibahas dalam uji kesukaan yaitu tentang rasa pada tablet dan penampilan tablet tiap formula. Hasil uji kesukaan terdiri dari tanggapan rasa dan penampilan pada setiap formula. Terdapat 20 responden dengan kriteria warga umum dan berusia 18-45 tahun. Responden terhadap rasa menghasilkan persentase yang berbeda pada ketiga formula. Untuk Formula I dari 20 responden didapatkan hasil 1 responden mengisi rasa pahit agak manis, 4 responden mengisi rasa agak pahit, dan 15 responden mengisi rasa pahit. Untuk Formula II dari 20 responden didapatkan hasil 2 responden mengisi rasa pahit agak manis, 5 responden mengisi rasa agak pahit, dan 13 responden mengisi rasa pahit. Serta, untuk Formula III dari 20 responden didapatkan hasil 2 responden mengisi rasa pahit agak manis, 8 responden mengisi rasa agak pahit, dan 10 responden mengisi rasa pahit. Dari hasil tersebut, responden yang menyatakan tablet terasa pahit lebih banyak, yaitu untuk Formula I sebanyak $75 \%$, Formula II sebanyak 65\%, dan Formula III sebanyak 50\%. Hal ini disebabkan oleh ekstrak yang digunakan merupakan ekstrak etanol daun kelor yang pada dasarnya memiliki rasa pahit, seperti menurut Shuntang (2018) bahwa daun kelor mengandung saponin yang menyebabkan rasa pahit pada daun kelor. Penggunaan bahan pengisi seperti laktosa juga tidak begitu berpengaruh pada rasa karena laktosa tidak terlalu manis sehingga tidak dapat menutupi rasa pahit dengan sempurna. Penggunaan bahan pemanis yang tidak dikombinasi juga tidak dapat menutupi rasa pahit dengan baik.

Responden terhadap penampilan juga menghasilkan persentase yang berbeda pada ketiga formula. Untuk Formula I dari 20 responden didapatkan hasil 13 responden mengisi penampilan sangat suka, 5 responden mengisi penampilan suka, dan 2 responden mengisi penampilan kurang suka. Untuk Formula II dari 20 responden didapatkan hasil 10 responden mengisi penampilan sangat suka, 9 responden mengisi penampilan suka, dan 1 responden mengisi penampilan kurang suka. Serta, untuk Formula III dari 20 responden didapatkan hasil 8 responden mengisi penampilan sangat suka, 10 responden mengisi penampilan suka, dan 2 responden mengisi penampilan kurang suka. Hasil uji tanggapan responden terhadap penampilan sebagian besar responden menyatakan lebih menyukai tablet kunyah pada Formula I yaitu sebesar $65 \%$. Penampilan tablet yang dihasilkan oleh Formula I lebih berwarna dari pada tablet yang dihasilkan dari Formula II dan III yang cenderung lebih pucat sehingga kurang menarik. Hal ini disebabkan oleh pembuatan tablet Formula I kadar 


\section{Prosiding Seminar Nasional Kesehatan Lembaga Penelitian dan Pengabdian Masyarakat Universitas Muhammadiyah Pekajangan Pekalongan}

amilumnya lebih kecil dibanding dengan formula lainnya, sehingga tidak ada penambahan warna dari amilumnya sehingga menghasilkan tablet yang berwarna hijau pekat.

\section{Kesimpulan}

Evaluasi penggunaan pati ganyong sebagai bahan pengikat pada tablet kunyah ekstrak etanol daun kelor menghasilkan tablet yang memenuhi syarat dalam evaluasi granul dan evaluasi tablet. Dari ketiga formula, kadar amilum yang mendekati sempurna terdapat pada konsentrasi amilum $10 \%$ atau pada Formula III. Dengan nilai dalam evaluasi granul yang meliputi uji kadar air yaitu 0,00\%, uji kompresibilitas 7,89\%, uji sudut diam 32,210, uji laju alir 4,59 detik. Dan nilai dalam evaluasi tablet yang meliputi uji penampilan fisik tidak ada kerusakan, uji organoleptis dengan rasa pahit agak manis, uji keseragaman ukuran dengan diameter 12,00 mm tebal tablet 4,69 mm, uji keseragaman bobot dengan rata-ratanya 507,9 mg, uji kekerasan 5,16 $\mathrm{kg}$, uji kerapuhan 0,36\%, uji waktu hancur 4 menit 30 detik.

\section{Referensi}

[1] Amiruddin, Prisiska, F., dan Gusmayadi, I., 2021, Pengaruh Kombinasi Manito/Sorbitol Sebagai Pengisi Tablet Kunyah Ekstrak Etanol 96\% Daun Sirsak (Annona muricata L.), Farmasains, Vol. 8, No. 1.

[2] Ansel H.C., 2014, Bentuk Sediaan Farmasetis dan Sistem Penghantaran Obat, 9th (eds), Afifah, H., \& Ningsih, T., Penerbit Buku Kedokteran EGC.

[3] Egeten, K.R., Yamlean, P.V.Y., Supriati, H.S., 2016, Formulasi dan Pengujian Sediaan Granul Effervescent Sari Buah Nanas (Ananas comosus L. (Merr.)), Jurnal IImiah Farmasi, Vol. 5, No. 3.

[4] Hadisoewignyo L., dan Fudholi A., 2013, Sediaan Solida, Pustaka Pelajar, Yogyakarta.

[5] Husni, P., Fadhiilah, M. L., dan Hasanah, U., 2020, Formulasi dan Uji Stabilitas Fisik Granul Instan Serbuk Kering Tangkai Genjer (Limnocharis flava (L) Buchenau.) sebagai Suplemen Penambah Serat, Jurnal Ilmiah Farmasi Farmasyifa Vol. 3 No. 1.

[6] Ifmaily, 2018, Penetapan Kadar Pati Buah Sukun (Artocarpus altilis L.) dengan Metode Luff Schoorl, Chempublish Journal, 4(1): 1-10.

[7] Indrianti, D., Prima, A. P., Musadad, A. M., 2017, Fosforilasi Pati Ganyong sebagai Pengikat pada Tablet Parasetamol Menggunakan Sodium Tripoliphosphat, Prosiding Farmasi, Vol. 3, No. 2.

[8] Kartika, D.H., Mutmainah., dan Mufrod, 2012, Pengaruh Peningkatan Konsentrasi Pati Biji Alpukat (Persea Americana Mill) Sebagai Bahan Pengikat Terhadap Karakteristik Fisik Granul dan Tablet Ekstrak Alang - Alang (Imperata clyndrica Linn), Majalah Obat Tradisional. 17 (2) : 22 - 26.

[9] Khaidiri, S., Murrukmihadi, M., \& Kusuma, A. P., 2015, Formulasi Tablet Ekstrak Kangkung Air (Ipomoea Aquatica F.) dengan Variasi Kadar Amilum Manihot sebagai Bahan Penghancur, Jurnal Ilmiah Farmasi, 11(1). 


\section{Prosiding Seminar Nasional Kesehatan Lembaga Penelitian dan Pengabdian Masyarakat Universitas Muhammadiyah Pekajangan Pekalongan}

[10] Lachman L., Herbert, A. L. \& Joseph, L. K., 2012, Teori dan Praktek Farmasi Industri II, Edisi III, 648-650, Penerbit Universitas Indonesia, Jakarta

[11] Muflikhah, N., 2017, Formulasi Sediaan Tablet Kunyah Ekstrak Etanol Daun Kelor (Moringa oleifera L) dengan Penambahan Variasi Pengisi Sorbitol-Sukrosa mengunakan Metode Granulasi Basah, Skripsi, Semarang: Universitas Wahid Hasyim Semarang.

[12] Riawati, 2013, Formulasi Tablet Kunyah Attapulgit dengan Variasi Konsentrasi Bahan Pengikat PVP Menggunakan Metode Granulasi Basah, Pontianak : Universitas Tanjung Pontianak.

[13] Setiawan, T., Susilaningsih, N., Saktini, F., 2018, Pengaruh Pemberian Ekstrak Daun Kelor (Moringa Oleifera L.) Dosis Bertingkat Terhadap Gambaran Mikroskopis Gaster Tikus Wistar Jantan yang Diinduksii Formalin, Jurnal Kedokteran Diponegoro, Vol. 7, No. 2.

[14] Shuntang, G., 2018, Current topics in saponins and the bitter taste, Research in Medical \& Engineering Sciences, 5(1), 390-391.

[15] Siregar, C.J.P., dan Wikarsa, S., 2015, Teknologi Farmasi Sediaan Tablet Dasar Dasar Praktis. Jakarta : Buku Kedokteran EGC. 